\title{
PENGEMBANGAN MEDIA PEMBELAJARAN PEMASANGAN INSTALASI LISTRIK DAN VIDEO TUTORIAL INSTALASI LISTRIK DALAM MATA KULIAH DASAR-DASAR INSTALASI DI PROGRAM STUDI PENDIDIKAN TEKNIK ELEKTRO UNDIKSHA
}

\author{
M. D. Hendra Sanjaya ${ }^{1}$, A. Adiarta ${ }^{2}$, N. Santiyadnya ${ }^{3}$ \\ 1,2,3Prodi Pendidikan Teknik Elektro, Universitas Pendidikan Ganesha, Singaraja \\ e-mail: dwisanjaya193@gmail.com, agus.adiarta@undiksha.ac.id, santiyadnya@undiksha.ac.id
}

\begin{abstract}
Abstrak
Penelitian ini bertujuan 1) membuat media pembelajaran instalasi listrik dan video tutorial pemasangan instalasi listrik di Program Studi Pendidikan Teknik Elektro, 2) untuk mengetahui tingkat kelayakan terhadap media pembelajaran instalasi listrik, 3) untuk mengetahui respon mahasiswa setelah menggunakan media pembelajaran instalasi listrik. Metode yang digunakan dalam penelitian ini adalah metode R\&D (Research and Development). Hasil uji validasi ahli materi memperoleh hasil $100 \%$ dengan kualifikasi sangat layak, hasil uji validasi ahli media memperoleh hasil 99,31\% dengan kualifikasi sangat layak, hasil uji kelompok kecil memperoleh hasil $88,60 \%$ dengan kualifikasi sangat baik, dan hasil uji kelompok besar memperoleh hasil $96,40 \%$ dengan kualifikasi sangat baik. Berdasarkan hasil penelitian, media pembelajaran instalasi listrik layak digunakan dalam melakukan proses pembelajaran pada mata kuliah Dasar-dasar Instalasi pada Program Studi Pendidikan Teknik Elektro Undiksha.
\end{abstract}

Kata kunci: Pengembangan media pembelajaran, Trainner instalasi listrik

\begin{abstract}
This study aims at 1) developing electrical installation learning media and a video tutorial on how to install the media in Basics of Installation course in the Electrical Engineering Education Program Study; 2) determining the level of feasibility of electrical installation learning media; 3) determining the response of students after using electrical installation learning media. The method applied in this study was R\&D (Research and Development). The result of validation test by material expert obtained the percentage of $100 \%$ with very decent qualification. Meanwhile, the result of validation test by media expert obtained $99.31 \%$ with very decent qualification as well. Then, the result of the small group test obtained the percentage of $88.60 \%$ with very good qualification and the result of large group test obtained $96.40 \%$ with very good qualification too. Based on the results of the study, the electrical installation learning media was suitable to be used in conducting the learning process on Basics of Installation course in Electrical Engineering Education Program Study at Ganesha University of Education.
\end{abstract}

Keywords: Development of Learning Media, Trainner of Electrical Installation

\section{Pendahuluan}

Pada abad modern saat ini, listrik merupakan salah satu kebutuhan primer bagi manusia dan sebagai sumber daya ekonomis yang berguna bagi manusia. Kebutuhan listrik akan semakin meningkat sesuai dengan perkambangan teknologi. Penggunaan listrik merupakan suatu hal yang penting dalam kehidupan baik itu dalam sektor rumah tangga, penerangan, komunikasi, industri dan lain sebagainya. Listrik dapat berguna dan bermanfaat bagi manusia jika penginstalasian listrik sesuai dengan peraturan. Begitu pula sebaliknya, listrik akan sangat merugikan dan berbahaya bagi manusia jika penginstalasian tidak mengikuti aturan yang berlaku. Untuk medapatkan keuntungan dari penggunaan listrik maka dibutuhkan tenaga ahli dalam penginstalasian listrik supaya listrik dapat bermanfaat dan berguna bagi manusia. 
Pada Program Studi Pendidikan Teknik Elektro di Universitas Pendidikan Ganesha (UNDIKSHA) yang merupakan salah satu perguruan tinggi di Indonesia yang mampu menciptakan tenaga ahli dalam penginstalasian listrik. Berdasarkan struktur kurikulum yang diatur dalam keputusan Rektor Undiksha tentang buku pedoman studi, dijelaskan bahwa DasarDasar Intalasi Listrik merupakan kelompok mata kuliah bidang keahlian (MKBK) dengan jumlah Satuan Kredit Semester (SKS) yaitu 3 SKS, dimana setiap SKS dialokasikan waktunya 60 menit. Seorang mahasiswa yang kuliah dibidang kelistrikan wajib mengetahui tentang pemasangan instalasi listrik dan mengetahui komponen-komponen apa saja yang digunakan dan fungsi dari komponen tersebut, serta mahasiswa juga harus memiliki keterampilan memasang instalasi listrik sesuai dengan PUIL.

Berdasarkan hasil observasi dan wawancara dengan dosen pengampu mata kuliah Dasar - Dasar Instalasi, kegiatan praktek yang dilakukan pada mata kuliah tersebut masih belum maksimal. Hal ini dikarenakan oleh beberapa faktor yaitu: 1. Belum ada ruangan yang dikhususkan untuk praktek instalasi listrik, 2. Ketersedian media pembelajaran masih kurang maksimal, 3. Belum tersediannya modul pembelajaran praktek instalasi listrik dan video tutorial pemasangan instalasi listrik, 4. Kurang efektifnya waktu praktek, dikarenakan dosen pengampu mata kuliah Dasar - Dasar Instalasi Listrik dan mahasiswa harus mempersiapkan terlebih dahulu alat dan bahan yang dibutuhkan maka akan memerlukan banyak waktu. Kegiatan praktek merupakan kegiatan untuk melatih keterampilan peserta didik dalam memasang instalasi listrik.

Berdasarkan uraian diatas, maka dikembangkan suatu media pembelajaran pemasangan instalasi listrik dan video tutorial instalasi listrik di Program Studi Pendidikan Teknik Elektro Undiksha sehingga mahasiswa dapat melakukan praktek dengan baik, nyaman dan tercapai apa yang menajdi tujuan dari praktek tersebut. Media pembelajaran pemasangan instalasi listrik berbentuk trainer yang dilengkapi dengan video tutorial pemasangan dan modul pemasangan instalasi listrik.

Dengan adanya media pembelajaran pemasangan instalasi listrik tersebut mahasiswa diharapakan mampu memiliki kemampuan dan pemahaman dalam penginstalasian listrik. Berdasarkan latar belakang yang diuraikan diatas, dapat dirumuskan permasalahan yaitu: (1) Bagaimanakah desain media pembelajaran instalasi listrik dan video tutorial pemasangan instalasi listrik. (2). Apakah media pembelajaran instalasi listrik layak digunakan dalam mata kuliah dasar-dasar Instalasi. (3). Bagaimanakah respon mahasiswa setelah menggunakan media pembelajaran instalasi listrik.

Sesuai dengan latar belakang dan juga perumusan masalah yang telah dipaparkan, jadi dapat diuraikan tujuan dari pengembangan ini adalah (1) Membuat media pembelajaran instalasi listrik dan video tutorial pemasangan instalasi listrik di Program Studi Pendidikan Teknik Elektro Undiksha (2) untuk mengetahui tingkat kelayakan terhadap media pembelajaran instalasi. (3) untuk mengetahui respon mahasiswa setelah menggunakan media pembelajaran instalasi listrik.

\section{Metode}

Dari rumusan masalah dan tujuan penelitian penelitian yang telah dipaparkan dengan judul penelitian Pengembangan Media Pembelajaran Pemasangan Instalasi Listrik dan Video Tutorial Instalasi Listrik Dalam Mata Kuliah Dasar - Dasar Instalasi Listrik di Program Studi Pendidikan Teknik Elektro merupakan penelitian pengembangan (research and development). Metode penelitian ini merupakan metode penelitian yang digunakan untuk menghasilkan produk tertentu dan menguji keefektifan produk tertentu, dan menguji kelayakan produk tersebut Sugiyono, 2011: 407).

Pada penelitian ini menggunakan model pengembangan sugiyono, menurut sugiyono (2011: 409), ada 10 langkah-langkah dalam penelitian R\&Danatar lain: (1) Potensi dan Masalah, (2) Pengumpulan Data, (3) Desain Produk, (4) Validasi Desain, (5) Revisi Desain, (6) Uji coba produk, (7) Revisi Produk, (8) Uji Coba Pemakaian, (9) Revisi Produk, (10) Produksi Masal. 
Menurut Santiyadnya (2015:152) untuk mendapatkan data dan permasalahan melalui wawancara dan observasi langsung kepada tenaga pendidik pengampu mata kuliah Dasar Dasar Instalasi terkait dengan penelitian yang dibuat. Dalam penelitian ini, peneliti menguji produk pada subjek penelitian yaitu mahasiswa semester VI Program Studi Pendidikan Teknik Elektro, peneliti menggunakan mahasiswa semester VI karena mahasiswa semester VI telah mengambil mata kuliah Dasar- Dasar Instalasi. Metode pengumpulan data Perancangan yang disusun dalam penelitian ini adalah sebagai berikut. (1) Data Validasi Ahli dipeoleh dari lembar validasi yang diberikan kepada para ahli media dan materi untuk menilai dan menelaah media pembelajaran yang dikembangkan. Hasil telah digunakan sebagai masukan untuk merevisi/ menyempurnakan media pembelajaran yang digunakan. (2) Data Respon mahasiswa, Untuk pengumpulan data dari respon mahasiswa mengenai media pembelajaran yang di kembangkan dilakukan dengan metode angket.

Instrument penelitian atau alat yang digunakan untuk mengumpulkan data dalam suatu penelitian. 1) Lembar Validasi Media Pembelajaran, Instrumen ini digunakan untuk mendapatkan data mengenai pendapat para ahli (validator) terhadap media pembelajaran dikembangkan sehingga menjadi acuan/pedoman dalam merevisi media pembelajaran yang dikembangkan, yaitu instrumen uji kelayakan untuk ahli materi dan instrumen uji kelayakan untuk ahli media. 2) Lembar Angket Respon Mahasiswa Instrumen ini disusun untuk mendapatkan data mengenai pendapat mahasiswa terhadap materi dan media pembelajaran yang dikembangkan.

Teknik Analisa data pada penelitian ini adalah dilakukan dengan analisis menggunakan teknik deskriptif presentase serta jenis data yang digunakan dalam penelitian ini adalah data kuantitatif. Dalam penilaian validasi media dilakukan dengan beberapa ktriteria yaitu sangat setuju, setuju, cukup setuju, tidak setuju, dan sangat tidak setuju. Dimana masing-masing item memiliki skor. Rentang persentase dan kriteria kualitatif uji kelayakan media dapat ditetapkan pada Tabel 1 dan rentang persentase respon mahasiswa dapat dilihat pada Tabel 2.

Tabel 1. Kualifikasi tingkat kelayakan berdasarkan persentase (Sugiyono, 2013:305)

\begin{tabular}{ccc}
\hline No & Interval (\%) & Kriteria \\
\hline 1 & $84-100$ & Sangat Layak \\
2 & $68-84$ & Layak \\
3 & $52-68$ & Cukup Layak \\
3 & $36-52$ & Kurang Layak \\
4 & $20-36$ & Tidak Layak \\
\hline
\end{tabular}


Tabel 2. Kualifikasi tingkat respon mahasiswa berdasarkan persentase (Umi Narimawati, 2007: 85)

\begin{tabular}{ccc}
\hline No & Interval (\%) & Kriteria \\
\hline 1 & $84-100$ & Sangat Baik \\
2 & $68-84$ & Baik \\
3 & $52-68$ & Cukup \\
3 & $36-52$ & Kurang \\
4 & $20-36$ & Sangat Kurang \\
\hline
\end{tabular}

\section{Hasil dan Pembahasan}

Pengujian media pembelajaran yang telah dikembangkan peneliti dilakukan sebanyak empat kali. Pada tahap pertama dilakukan uji validasi media yang diisi oleh validator dari dosen Program Studi Pendidikan Teknik Elektro yaitu Dr. I Gede Ratnaya.S.T., M.Pd. setelah itu, tahap kedua uji validasi materi diisi oleh validator dosen pengampu mata kuliah Dasar - Dasar Instalasi yaitu Dr. Agus Adiarta.S.T., M.T. Tahap ketiga uji produk lapangan kelompok kecil yang dimana menggunakan mahasiswa semester VI Program Studi Pendidikan Teknik Elektro sebanyak 5 orang. Setelah mendapatkan respon dari pengujian kelompok kecil, maka tahap terakhir adalah melakukan pengujian kelompok besar, menggunakan 15 orang mahasiswa semester VI Program Studi Pendidikan Teknik Elektro. Tujuan dari penelitian ini adalah (1) untuk mengetahui tingkat kelayakan media pembelajaran instalasi listrik yang dikembangkan peneliti. (2) untuk mengetahui respon mahasiswa dengan media pembelajaran instalasi listrik untuk meningkatkan keterampilan dalam instalasi listrik.

Untuk penelitian tahap pertama dilakukan beberapa kegiatan yaitu (1) pengumpulan data (2) desain produ (3) validasi (4) revisi desain. Setelah dilakukannya tahap pertama, kemudian tahap selanjtunya, dilakukan pembuatan produk, setelah prdouk selesai maka akan dilakukan revisi produk yang telah dibuat sebelum diuji kelayakannya. Tahap selanjutnya yaitu melakukan uji produk, yang dimana dilakukan sebanyak empat kali yaitu uji validasi ahli media, uji ahli materi, uji kelompok kecii dan uji kelompok besar.

Perolehan presentase dari uji ahli media mendapat hasil 99,31\%. Hasil tersebut dikategorikan sangat layak dan ahli media memberikan masukkan yaitu penambahan wiring diagram pada media pembelajaaran. Perolehan presentase dari uji ahli materi yang langsung diisi oleh dosen pengampu mata kuliah Dasar - Dasar instalasi mendapat hasil $100 \%$. Hasil tersebut dikategorikan sangat layak untuk digunakan sebagai media pembelajaran pada mata kuliah Dasar - Dasar Instalasi. Setelah melakukan pengujian validasi ahli media dan juga materi, maka selanjutnya dilakukan uji produk kelompok kecil.

Dari uji kelompok kecil, media pembelajaran mendapatkan hasil 88,66\% yang dimana hasil tersebut dikategorikan sangat layak, serta terdapat masukkan dan saran dari mahasiswa untuk ditambahkan wiring diagram agar mahasiswa lebih memahami jalur pengkabelan instalasi listrik. Kemudian, media yang telah diisi wiring diagram, selanjutnya akan diuji kembali pada kelompok besar. Pada kelompok besar mendapatkan hasil 96,40\%. Hasil tersebut dapat dikategorikan sangat layak untuk digunakan pada mata kuliah Dasar - Dasar Instalasi. Untuk hasil uji produk keseluruhan yang telah didapatkan dapat dilihat pada Tabel 3. 
Tabel 3. Hasil

(Sumber: Hasil Pengamatan Sendiri)

\begin{tabular}{cccc}
\hline Uji & Total poin & $\%$ & Kreteria \\
\hline Uji Media & 144 & $99,31 \%$ & Sangat layak \\
Uji Materi & 90 & $100 \%$ & Sangat layak \\
Uji Kelompok kecil & 443 & $88,60 \%$ & Sangat Baik \\
Uji Kelompok Besar & 1446 & $96,40 \%$ & Sangat Baik \\
\hline
\end{tabular}

\section{Kesimpulan dan Saran}

Berdasarkan hasil dan pembahasan dapat disimpulkan: media pembelajaran pemasangan instalasi listrik dapat digunakan untuk membantu proses pembelajaran, layak digunakan sebagai media pembelajaran dan mendapatkan respon yang baik dari mahasiswa pada mata kuliah Dasar - Dasar Instalasi di Program Studi Pendidikan Teknik Elektro Undiksha. Hasil uji validasi ahli materi memperoleh hasil $100 \%$ dengan kualifikasi sangat layak, hasil uji validasi ahli media memperoleh hasil 99,31\% dengan kualifikasi sangat layak, hasil uji kelompok kecil memperoleh hasil $88,60 \%$ dengan kualifikasi sangat baik, dan hasil uji kelompok besar memperoleh hasil $96,40 \%$ dengan kualifikasi sangat baik.

Adapun saran yang disampaikan terhadap media pembelajaran instalasi listrik yaitu sebagai berikut. (1) Media pembelajaran ini dirancang kokoh dan bersifat portabel. Untuk penggunaan media pembelajaran harus sesuai dengan arahan dari dosen atau tenaga pendidik, serta mengikuti penggunaan pada video tutorial dan buku panduan penggunaan. Dalam waktu tertentu, perlu diperhatikan perawatan pada media supaya media dapat digunakan dalam waktu yang lama. (2) Media pembelajaran diharapkan dapat membantu tenaga pendidik atau dosen pengampu mata kuliah Dasar - Dasar Instalasi untuk proses pembelajaran, sehingga mahasiswa akan lebih cepat mengerti dan memahami tentang penginstalasian listrik. (3) Dengan adanya media pembelajaran instalasi listrik diharapkan mahasiswa dapat lebih berinovasi dan mampu meningkatkan kemampuan dalam penginstalasian listrik. (4) Untuk penelitan pengembangan selanjutnya dapat menambah cakupan materi sakelar silang dan sistem instalasi 3 phasa menggunakan media yang dikembangkan sehingga media pembelajaran yang dikembangkan dapat memenuhi kebutuhan proses praktikum penginstalasian listrik.

\section{Daftar Rujukan}

Achmad Sugandi, dkk. 2007. Teori Pembelajaran. Semarang: UPT MKK Universitas Negeri Semarang.

Achmad, Sugandi, Teori Pembelajaran. Bandung : PT. Remaja Rosdakarya, 2000.

Arrozi, Muhammad Ihwan. 2018. Pengembangan Media Praktikum Portabel Pada Mata Kuliah Instalasi Tata Cahaya Di Prodi S1 Pendidikan Teknik Elektro. Fakultas Teknik dan Kejuruan, Universitas Pendidikan Ganesha. 
Arsyad, Azhar. 2011. Media Pembelajaran. Jakarta: PT Raja Grafindo Persada.

Arsyad, Azhar.2011. Media Pembelajaran. Jakarta: Raja Gafindo.

Arsyad, H. Rayandra. 2012. Kreatif Mengembangkan Media Pembelajaran. Jakarta: Referensi Jakarta.

Badan Standarisasi Nasional. 2000. Persyaratan Umum Instalasi Listrik 2000 (PUIL 2000), Jakarta: BSN.

Dewi, Angraini. 2015. Pembutan Trainner Instalasi Listrik Sebagai Media Pembelajaran Untuk Mata Kuliah Teknik Instalasi Listrik (Studi Pada Program Studi Pendidikan Teknik Elektro) Universitas Negeri Jakarta. Fakultas Teknik, Universitas Negeri Jakarta.

Kiswanto, Heri. 2013. Media Pembelajaran Pemasangan Instalasi Penerangan Listrik Bangunan Bertingkat Pada Mata Pelajaran Teknik Instalasi Listrik Di SMK Negeri 1 Semarang. Fakultas Teknik. Universitas Negeri Semarang.

Kunandar. 2007. Guru Profesional: Implementasi Kurikulum Tingkat SatuanPendidikan (KTSP) dan Sukses dalam Sertifikasi Guru. Jakarta: RajawaliPers.

Linsley, Trevor. 2009. Instalasi Listrik Dasar. Edisi ke 3. Diterjemahkan oleh: Mirza Satriawan,Ph.D. Jakarta. Penerbit Erlangga.

Linsley,Travor. 2009. Instalasi Listrik Tingkat Lanjut. Edisi ke 3. Diterjemahkan oleh: Wiwit Kastawan. Jakarta: Erlangga.

Miles, B.M \& Huberman, M.A.1992. Analisis Data Kualitatif. Penerjemah: Rohidi, R.T. Universitas Indonesia. Jakarta.

Mulyasa. 2009. Standar Kompetensi dan Setifikasi guru. Bandung: Remaja Rosda Karya Peraturan Pemerintah Nomor 19 Tahun 2005 tentang Standar Nasional Pendidikan. Tersedia pada: (http://telkomuniversity.ac.id/images/uploads/PP_No._19_ Tahun_2005.pdf). Diunduh pada tanggal 22 Desember 2016.

Narimawati, Umi. 2007. Riset Manajemen Sumber Daya Manusia. Jakarta: Agung Media. Neidle, Michael. 1999. Teknologi Instalasi Listrik. Edisi ke 3. Diterjemahkan oleh : Sahat

Pakpahan. Jakarta. Penerbit Erlangga,

Riyana, Cheppy. 2007. Pedoman Pengembangan Media Video. Jakarta: P3AI UPI.

Santiyadnya, Nyoman (2015), Evaluasi Program Pelaksanaan Uji Kompetensi Keahlian Produktif Di SMK Negeri 3 Singaraja

Sudaryono; Margono, Gaguk; Rahayu, Wardani . 2013."Pengembangan Instrumen Penelitian Pendidikan"Yogyakarta: Graha IImu.

Sudrajat, Akhmad. 2008. Pengertian Pendekatan, Strategi, Metode, Teknik dan Model Pembelajaran. Bandung : Sinar Baru Algensindo.

Sugiyono, 2009, Metode Penelitian Kuantitatif, Kualitatifdan R\&D, Bandung : Alfabeta. Sugiyono. 2010. Statistika Untuk Penelitian. Bandung: Alfabeta.

Sugiyono. 2015. Metode Penelitian Pendidikan (Pendekatan Kualitatif, Kuantitatif, dan R\&D). Bandung: Alfabeta. 
Taufiqurrokhman. 2013. Media Pembelajaran Berbasis Multimedia Memasang Instalasi Listrik Bangunan Sederhana Mata pelajaran Kompetensi Kejuruan Teknik Pemanfaatan Tenaga Listrik Kelas $X$ (TITL) SMK Negeri 1 Semarang. Fakultas Teknik, Universitas Negeri Semarang. 